\title{
Conus Medullaris
}

National Cancer Institute

\section{Source}

National Cancer Institute. Conus Medullaris. NCI Thesaurus. Code C12832.

The terminal, cone-shaped end of the spinal cord. 